\title{
A Linear Inverse Model of Tropical and South Pacific Climate Variability: Optimal Structure and Stochastic Forcing
}

\author{
Jiale Lou, ${ }^{\mathrm{a}, \mathrm{b}}$ Terence J. O'KAne, ${ }^{\mathrm{c}, \mathrm{d}}$ AND Neil J. HolbrooK ${ }^{\mathrm{a}, \mathrm{d}}$ \\ ${ }^{a}$ Institute for Marine and Antarctic Studies, University of Tasmania, Hobart, Tasmania, Australia \\ ${ }^{\mathrm{b}}$ ARC Centre of Excellence for Climate System Science, University of Tasmania, Hobart, Tasmania, Australia \\ ${ }^{\mathrm{c}}$ CSIRO Oceans and Atmosphere, Hobart, Tasmania, Australia \\ ${ }^{\mathrm{d}}$ ARC Centre of Excellence for Climate Extremes, University of Tasmania, Hobart, Tasmania, Australia
}

(Manuscript received 19 December 2019, in final form 4 August 2020)

\begin{abstract}
A stochastically forced linear inverse model (LIM) of the combined modes of variability from the tropical and South Pacific Oceans is used to investigate the linear growth of optimal initial perturbations and to identify the spatiotemporal features of the stochastic forcing associated with the atmospheric Pacific-South American patterns 1 and 2 (PSA1 and PSA2). Optimal initial perturbations are shown to project onto El Niño-Southern Oscillation (ENSO) and South Pacific decadal oscillation (SPDO), where the inclusion of subsurface South Pacific Ocean temperature variability significantly increases the multiyear linear predictability of the deterministic system. We show that the optimal extratropical sea surface temperature (SST) precursor is associated with the South Pacific meridional mode, which takes from 7 to 9 months to linearly evolve into the final ENSO and SPDO peaks in both the observations and as simulated in an atmosphere-forced ocean model. The optimal subsurface precursor resembles its peak phase, but with a weak amplitude, representing oceanic Rossby waves in the extratropical South Pacific. The stochastic forcing is estimated as the residual by removing the deterministic dynamics from the actual tendency under a centered difference approximation. The resulting stochastic forcing time series satisfies the Gaussian white noise assumption of the LIM. We show that the PSA-like variability is strongly associated with stochastic SST forcing in the tropical and South Pacific Oceans and contributes not only to excite the optimal initial perturbations associated with ENSO and the SPDO but in general to activate the entire stochastic SST forcing, especially in austral summer.
\end{abstract}

KEYWORDS: Climate variability; Inverse methods; Forecasting; ENSO; Oscillations; Pacific decadal oscillation

\section{Introduction}

The South Pacific decadal oscillation (SPDO; Chen and Wallace 2015; Lou et al. 2019) is the dominant mode of (inter)decadal climate variability in the South Pacific and is analogous to the Pacific decadal oscillation (PDO; Mantua et al. 1997) in the North Pacific. Lou et al. $(2019,2020)$ show that the SPDO represents not a single physical mode but instead combines different processes operating on a range of time scales. These processes include stochastic atmospheric forcing related to the Pacific-South American pattern (PSA; Mo 2000; O'Kane et al. 2017), El Niño-Southern Oscillation (ENSO) teleconnections from the tropics (e.g., Power and Colman 2006; Shakun and Shaman 2009), and subsurface oceanic processes (e.g., baroclinic Rossby waves in the southwest subtropical Pacific; O'Kane et al. 2014; Lou et al. 2019).

The idea that fast-moving atmospheric variability may act as stochastic forcing of slowly varying oceanic processes has been extensively discussed in the literature (e.g., Capotondi et al. 2018; Liu and Di Lorenzo 2018; Lou et al. 2019 and references therein). Hasselmann (1976) and Frankignoul and Hasselmann (1977) first proposed a stochastic climate model [i.e., the firstorder autoregressive (AR1) model] to illustrate how climate variations can arise as an integrated response to random excitation from weather disturbances. Numerous studies have since developed AR1 models to broadly investigate climatic

Corresponding author: Jiale Lou, jiale.lou@utas.edu.au reddening processes between stochastic forcing and slow variability (e.g., Newman et al. 2003; Power and Colman 2006; Shakun and Shaman 2009; Di Lorenzo and Ohman 2013; Capotondi et al. 2018; Lou et al. 2019).

Although useful conceptually, univariate AR1 models are limited by their simplicity (limitations are documented, e.g., in Newman 2007). Alternatively, the linear inverse model (LIM; Penland and Sardeshmukh 1995, hereafter PS95), which can be regarded as a multivariate analog of the univariate AR1 hypothesis, may be preferable to diagnose the underlying dynamics and understand the source of predictability.

The LIM has been widely applied to investigate the dynamics and predictability of atmospheric variability (von Storch and Xu 1990; Xu 1992; Schnur et al. 1993; Cavanaugh et al. 2014), tropical ENSO variability (Penland and Magorian 1993; PS95; Penland and Matrosova 2006; Newman et al. 2011; Gehne et al. 2014; Capotondi and Sardeshmukh 2015, 2017), Atlantic (multi-)decadal variability (Zanna 2012; Penland and Hartten 2014; Huddart et al. 2016), North Pacific (inter)decadal variability (Newman 2007; Alexander et al. 2008), and South Pacific (inter)decadal variability (Lou et al. 2020). Previous studies have shown that reduced-order multivariate LIMs are capable of revealing the appropriate linearized deterministic dynamics and provide competitive forecast skill relative to sophisticated nonlinear general circulation models.

In comparison with univariate AR1 models, where the onedimensional system decays monotonically in the absence of 
stochastic forcing [e.g., see Fig. 9 in Lou et al. (2019)], the multivariate LIM allows transient growth if the dynamics of the system are nonnormal in the absence of stochastic forcing, thereby making it possible to investigate optimal initial states that maximize the deterministic growth toward specified final states (e.g., PS95; Zanna 2012; Vimont et al. 2014; Capotondi and Sardeshmukh 2015; Thomas et al. 2018).

Many previous studies show that optimal growth maximizes at about 7-9 months for ENSO events in the tropical Pacific region (e.g., PS95; Newman et al. 2011; Vimont et al. 2014; Thomas et al. 2018). Vimont et al. (2014) suggest that the Pacific meridional mode (PMM) and thermocline variability are responsible for different types of ENSO events, while Capotondi and Sardeshmukh (2015) further show that different initial thermocline conditions can influence the selection of different types of ENSO events by investigating the linearized optimal evolution of different types of ENSO under the LIM framework.

How climate variability in the extratropical South Pacific affects the tropics is an active area of research. In a recent review paper of the PMM, Amaya (2019) summarized that the South Pacific meridional mode (SPMM; Zhang et al. 2014; Chung et al. 2019; Liguori and Di Lorenzo 2019) is triggered by internal atmospheric variability associated with the South Pacific Oscillation (SPO), which was recently proposed by You and Furtado (2017) to track the leading sea level pressure (SLP) mode of variability in the subtropical South Pacific $\left(10^{\circ}-45^{\circ} \mathrm{S}, 160^{\circ}-70^{\circ} \mathrm{W}\right)$.

While the physical connections between the SPMM and ENSO remain unclear, a few mechanisms have been proposed to link the extratropical South Pacific to the tropical Pacific. For example, some studies (Ding et al. 2014; Zhang et al. 2014; Lu et al. 2016; You and Furtado 2017) argue that the extratropical surface wind anomalies associated with the SPMM can propagate to the tropics via positive wind-evaporation-sea surface temperature (WES) feedback. Larson et al. (2018) suggest that the SPMM can act as the thermally driven sources of the tropical ENSO variability. In separate modeling studies, Liguori and Di Lorenzo (2019) and Chung et al. (2019) argue that the SPMM plays a key role in affecting tropical variability on decadal time scales by artificially suppressing the SPMM.

In addition, Okumura (2013) and Lou et al. (2019, 2020) show that the PSA variability is the key atmospheric driver of large-scale oceanic variability (e.g., the SPDO) in the South Pacific Ocean. In particular, Okumura (2013) and Lou et al. (2019) argue that the tropical Pacific is closely connected to the South Pacific, and the PSA variability can modulate or even trigger the tropical variability.

To quantify the contribution arising from the stochastic forcing, Penland and Hartten (2014) introduced a centered difference approximation to the tropical North Atlantic sea surface temperature (SST) system under the LIM framework. They found that the atmospheric North Atlantic Oscillation plays a significant role in affecting the predictability of the tropical North Atlantic SST. Recently, Thomas et al. (2018) suggest that stochastic forcing potentially contributes to the development of different types of ENSO by application of the same centered difference approximation developed by Penland and Hartten (2014).

While previous LIM studies have focused on the linearized deterministic dynamics of the combined tropical and South Pacific Oceans (Lou et al. 2020), our understanding of the role of stochastic forcing mechanisms in influencing the slowly varying linearized characteristics under a LIM framework is lacking. Motivated by the results of Lou. et al. (2019, 2020), we seek to better understand the role of stochastic forcing associated with the PSA variability in influencing ENSO and the SPDO under the LIM framework.

The paper is organized as follows: Section 2a describes the monthly and daily observational and simulated data used in this study. An overview of the LIM method and the design of the LIM experiments are presented in section $2 b$. The optimal initial conditions, their growth and evolution maximizing ENSO and the SPDO predictability are investigated in section $3 \mathrm{a}$. The role of stochastic forcing, as estimated from a centered difference calculation between observed and estimated LIM SST tendencies, is analyzed in section $3 b$. Section 4 provides the discussion and conclusions.

\section{Data and methods}

\section{a. Observed and simulated data}

The monthly observed and simulated data used in this study are the same as used in Lou et al. (2019, 2020). Specifically, monthly observed SSTs are from the Hadley Sea Ice and Sea Surface Temperature analysis (HadISST1.1; Rayner et al. 2003, and available at https:/www.metoffice.gov.uk/hadobs/ hadisst/data/download.html) for the years 1948-2007.

The model used was an atmosphere-forced ocean general circulation model, the Australian Community Climate EarthSystem Simulator-Ocean (ACCESS-O) configuration of the U.S. Geophysical Fluid Dynamics Laboratory (GFDL) Modular Ocean Model (MOM4p1) ocean-ice code (Delworth et al. 2006). The detailed model configuration has been described by O'Kane et al. (2014). ACCESS-O is forced by observed atmospheric fields from the Coordinated Ocean-Ice Reference Experiments (COREs; 1948-2007) (Griffies et al. 2009) and has 50 model levels in the vertical covering 0-6000 m. For comparison, the original $360 \times 300$ tripolar ACCESS-O ocean model grid has been interpolated to a regular $2.5^{\circ} \times 2.5^{\circ}$ grid in this study.

To understand the role of stochastic forcing, daily SST anomalies from the Optimum Interpolation Sea Surface Temperature data (OISST; Reynolds et al. 2002) over the period of 1982-2007 (26 years) were used (available at https://www.esrl.noaa.gov/psd/ thredds/catalog/Datasets/noaa.oisst.v2.highres/catalog.html). In addition, daily surface pressure reanalysis data over the same period of 1982-2007 are taken from the National Centers for Environmental Prediction-National Center for Atmospheric Research (NCEP-NCAR; available at https://psl.noaa.gov/data/ gridded/data.ncep.reanalysis.surface.html). All data have been remapped onto a common $2.5^{\circ} \times 2.5^{\circ}$ grid.

In performing the empirical orthogonal function/principal component (EOF/PC) analysis upon the variables, we make use of the monthly detrended anomalous data. That is, all the observed and simulated monthly data were first detrended at each grid point using linear regression. Then, the seasonal climatology was removed from the monthly data at each grid point to derive the monthly anomalies.

Meanwhile, the linear trend over the full data record (19822007) was removed from the daily OISST anomalous SST data 
and the daily NCEP-NCAR surface pressure data. The climatology was then removed from the daily surface pressure data to compute the daily surface pressure anomalies. For computational convenience, we ignored 29 February in all leap years in the daily data. Our results were not sensitive to this choice.

\section{b. The linear inverse model}

The principles and assumptions of the LIM used in this study are described in detail in Lou et al. (2020), and the interested reader is referred to that paper. Here, we present only a brief overview of the LIM method (see also PS95).

In the LIM framework, an $N$ component (i.e., $N=10$ in the present study) state vector of anomalies $\mathbf{X}$ evolves according to the following linear equation:

$$
\frac{d \mathbf{X}}{d t}=\mathbf{L X}+\mathbf{N}
$$

where the state vector $\mathbf{X}$ can be expressed as the sum of the linear deterministic dynamics, and a stochastic forcing term $\mathbf{N}$, which is assumed to be rapidly decorrelating white noise. The dynamical operator $\mathbf{L}$ in Eq. (1) is a stable constant $N \times N$ matrix describing feedback among the components of $\mathbf{X}$. The matrix $\mathbf{L}$ that describes the linear deterministic dynamics is given by

$$
\mathbf{L}=\tau_{0}^{-1} \ln \left[\mathbf{C}\left(\tau_{0}\right) \mathbf{C}(0)^{-1}\right],
$$

where $\mathbf{C}\left(\tau_{0}\right)$ and $\mathbf{C}(0)$ are the time lag and simultaneous covariance matrices of the state vector $\mathbf{X}$ at time lags $\tau_{0}$ and 0 , that is, $\mathbf{C}\left(\tau_{0}\right)=$ $\left\langle\mathbf{X}\left(t+\tau_{0}\right) \mathbf{X}^{\mathrm{T}}(t)\right\rangle$ and $\mathbf{C}(0)=\left\langle\mathbf{X}(t) \mathbf{X}^{\mathrm{T}}(t)\right\rangle$. The angle brackets here denote an ensemble average or a time average over all $t$ for variables with stationary statistics. In this study, $\tau_{0}=1$ month is used to ensure the stability of the LIMs. Lou et al. (2020) examined the sensitivity to using different choices of $\tau_{0}$ to estimate the dynamical operator $\mathbf{L}$, finding similar results to those presented here.

The most probable evolution $\mathbf{X}(t+\tau)$ of the system (PS95) is given by

$$
\mathbf{X}(t+\tau)=\mathbf{G}(\tau) \mathbf{X}(t)=e^{L \tau} \mathbf{X}(t),
$$

given a state $\mathbf{X}(t)$.

\section{c. Experimental design of the linear inverse model}

The EOF/PC analysis was applied as a prefilter to the monthly SST and vertically averaged temperature (VAT) anomalies in the tropical Pacific (TP; $\left.20^{\circ} \mathrm{S}-20^{\circ} \mathrm{N}, 120^{\circ} \mathrm{E}-60^{\circ} \mathrm{W}\right)$ and South Pacific (SP; $\left.70^{\circ}-22.5^{\circ} \mathrm{S}, 120^{\circ} \mathrm{E}-60^{\circ} \mathrm{W}\right)$, respectively.

For the LIM presented in this paper, we chose the state vector $\mathbf{X}$ following Lou et al. (2020):

$$
\begin{aligned}
& \mathbf{X}=\left[\begin{array}{c}
\mathbf{S S T}_{\mathrm{TP}} \\
\mathbf{S S T}_{\mathrm{SP}}
\end{array}\right] \quad(\mathrm{SST} \text {-only experiment }), \text { or } \\
& \mathbf{X}=\left[\begin{array}{c}
\mathbf{S S T}_{\mathrm{TP}} \\
\mathbf{S S T}_{\mathrm{SP}} \\
\mathbf{V A T}_{\mathrm{SP}}
\end{array}\right] \quad(\mathrm{SST}+\mathrm{VAT} \text { experiment }) .
\end{aligned}
$$

In the SST-only experiment, we considered a combination of both the TP SST (i.e., $\mathbf{S S T}_{\mathrm{TP}}$ ) and the SP SST (i.e., $\mathbf{S S T}_{\mathrm{SP}}$ ), whereas in the SST + VAT experiment we introduced additional subsurface variability in the form of the VAT calculated from 5 to $280 \mathrm{~m}$ in the upper South Pacific Ocean. We retained the leading four TP and six SP SST EOFs/PCs in the SST-only experiment and the leading two, six, and two EOFs/ PCs from the TP SST, SP SST, and SP VAT, respectively, in the SST + VAT experiment. As demonstrated in Lou et al. (2020), the choices of using the leading 10-16 EOFs/PCs in each LIM experiment to construct the state vector and the different combinations of the leading EOFs/PCs used from the different regions gives similar results.

In previous work, Lou et al. (2020) show that the LIM configurations used in this study are linear and stable and accurately represent the dynamics of the SPDO through a range of evaluation tests. They demonstrate that the dynamics of the SPDO can be accurately reconstructed based on two distinct spatial and temporal scales-one associated with interannual ENSO variability in the tropics and one oscillating on (inter) decadal time scales with a broader meridional structure in the tropical Pacific relative to the interannual ENSO.

\section{Results}

\section{a. Optimal growth}

The LIM methodology allows an objective determination of optimal initial states that evolve into the final specified events (e.g., the SPDO peak in this study), thereby providing an ideal framework to investigate optimal precursors and predictability (Capotondi and Sardeshmukh 2015).

The growth over any time interval $\tau$ can be written as the norm of the final state $\mathbf{X}(t)$ divided by the norm of the initial state $\mathbf{X}(0)$ (see PS95):

$$
\mu(\tau)=\frac{\|\mathbf{X}(t)\|^{2}}{\|\mathbf{X}(0)\|^{2}}=\frac{\mathbf{X}^{\mathrm{T}}(t) \mathbf{X}(t)}{\mathbf{X}^{\mathrm{T}}(0) \mathbf{X}(0)}=\frac{\mathbf{X}^{\mathrm{T}}(0) \mathbf{G}^{\mathrm{T}}(\tau) \mathbf{G}(\tau) \mathbf{X}(0)}{\mathbf{X}^{\mathrm{T}}(0) \mathbf{X}(0)} .
$$

The maximum amplification growth $\left\{\mu(\tau)_{\max }\right\}$ can be determined as the leading eigenvalue $\gamma_{1}$ (i.e., $\left.\left\{\mu(\tau)_{\max }\right\}=\gamma_{1}\right)$ of the matrix $\mathbf{G}^{\mathrm{T}}(\tau) \mathbf{G}(\tau)$, which is a real, symmetric and positivedefinite operator with real and positive eigenvalues $\left\{\gamma_{i}\right\}$ and orthonormal eigenvectors $\left\{\boldsymbol{\varphi}_{i}\right\}$.

Figure 1 shows the maximum amplification curve (MAC) of the SST-only (Figs. 1a-d) and SST + VAT (Figs. 1e,f) experiments. In the SST-only experiments, the linear deterministic systems experience maximum growth over time periods of 7 and 9 months for the HadISST and ACCESS-O LIMs, respectively (indicated by the vertical red lines in Fig. 1 and also shown in Table 1), consistent with the previous LIM studies of tropical ENSO variability (e.g., PS95; Newman et al. 2011; Vimont et al. 2014; Thomas et al. 2018).

If the MAC is less than unity, then no growth is possible without an additional stochastic forcing term, and all growth events tend to be unpredictable (e.g., PS95). With this in mind, we can see that no growth can be sustained by modal interferences for more than 16 and 22 months (Table 1) in the observed and simulated SST-only system (Figs. 1a-d), which defines an optimistic predictability limit (also referred to as potential predictability) of such growth events. However, this predictability limit does not consider the effects of stochastic 
(a) MA and Error Variance Curves

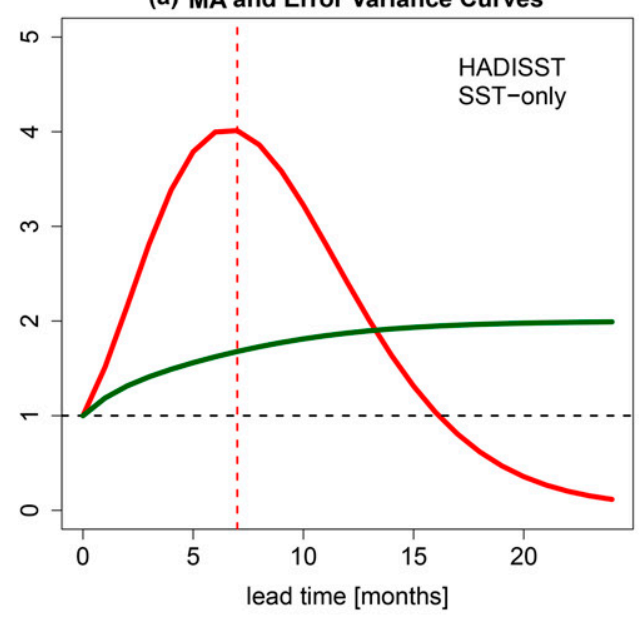

(c) MA and Error Variance Curves

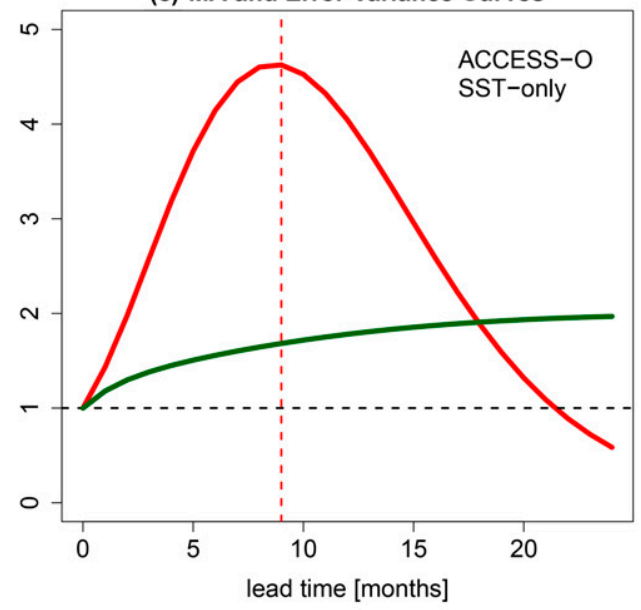

(e) MA and Error Variance Curves

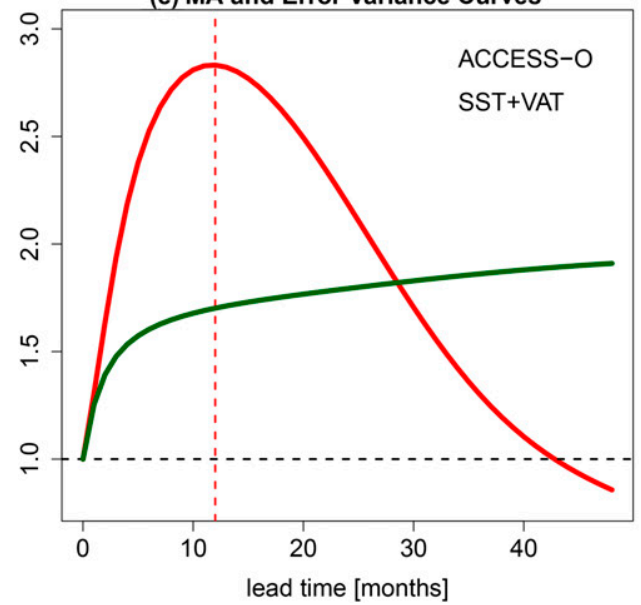

(b) MA Curve

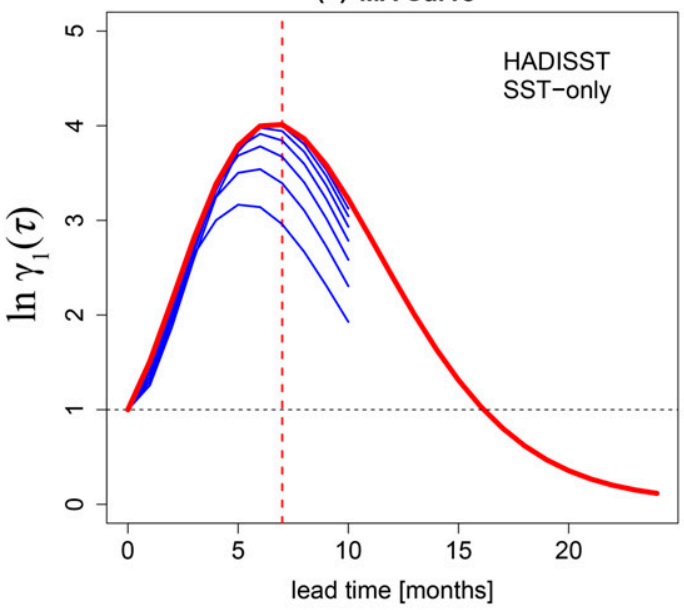

(d) MA Curve

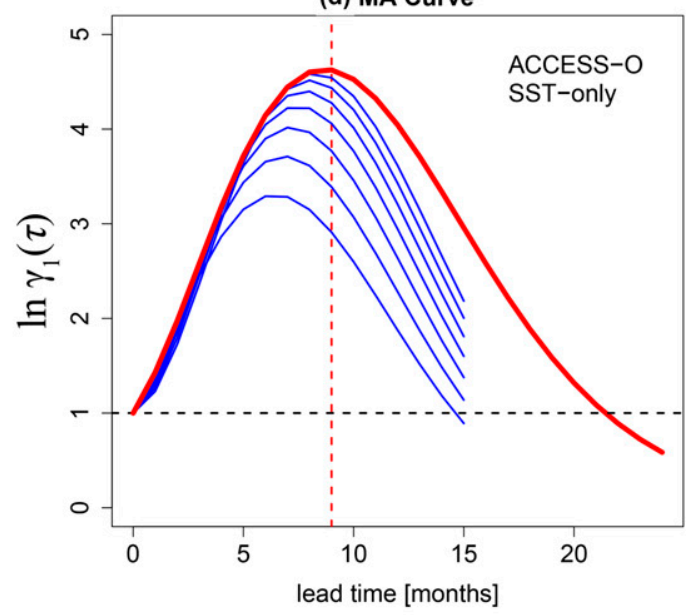

(f) MA Curve

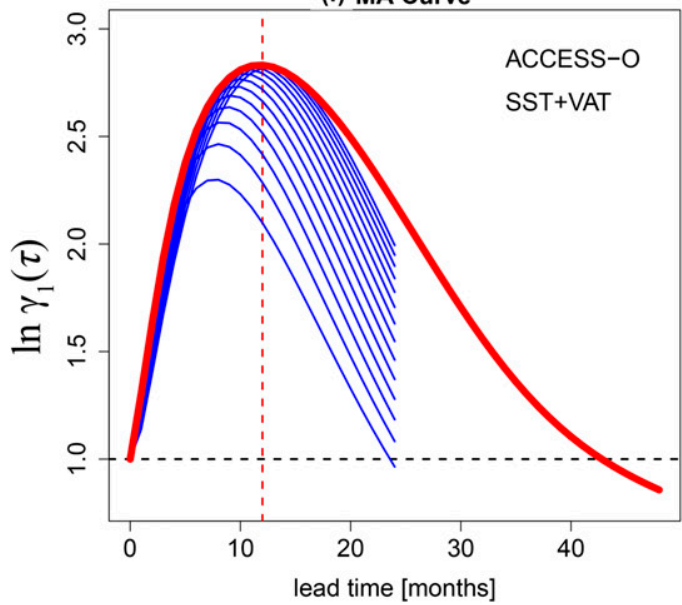

FIG. 1. The MAC (in red) of (a),(b) HadISST and (c),(d) ACCESS-O for the SST-only experiments, and (e),(f) ACCESS-O for the SST + VAT experiment. The average error energy growths $1+\mathbf{C}(0)-\mathbf{G}(\tau) \mathbf{C}(0) \mathbf{G}^{\mathrm{T}}(\tau)$ associated with the stochastic forcing are shown in green curves in (a), (c), and (e). The MAC of forecasts begun with initial conditions, optimized to give maximum growth at other $\tau$ 's ranging from 1 to 12 months, are given in blue curves in (b), (d), and (f). The horizontal black line indicates the unity threshold. The vertical red line indicates the optimal growth time. 
TABLE 1. The statistical properties of the MACs in the SST-only and SST + VAT experiments.

\begin{tabular}{llccc}
\hline \hline Dataset & Experiment & $\begin{array}{c}\text { Growth } \\
\text { time } \\
\text { (months) }\end{array}$ & $\begin{array}{c}\text { Potential } \\
\text { predictability } \\
\text { (months) }\end{array}$ & $\begin{array}{c}\text { Practical } \\
\text { predictability } \\
\text { (months) }\end{array}$ \\
\hline HadISST & SST-only & 7 & 16 & 14 \\
ACCESS-O & SST-only & 9 & 22 & 18 \\
& SST + VAT & 12 & 44 & 28 \\
\hline
\end{tabular}

forcing, which might further reduce the predictability of the growth events. Figures $1 \mathrm{a}$ and $1 \mathrm{c}$ show the error growth caused by the stochastic forcing term [i.e., $1+\mathbf{C}(0)-\mathbf{G}(\tau) \mathbf{C}(0) \mathbf{G}^{\mathrm{T}}(\tau)$ shown in the green curves]. The cross point between the MAC and error growth may give us more practical predictability of 14 and 18 months (Table 1) in the SST-only experiments taken from the HadISST and ACCESS-O LIMs, respectively. For signals from the linearized deterministic system to be predictable, it is therefore not only necessary that the MAC be greater than unity over some time interval $\tau$, but that it be greater than the error growth over the same time interval.

When considering the subsurface processes (i.e., SST + VAT experiment), the system experiences maximum growth over a much longer time period of about 12 months (Table 1 ) relative to those in the SST-only experiments. The predictability limit of the growth event is around 44 months (Table 1) without considering the error growth from the stochastic forcing. The error growth associated with the unpredictable stochastic forcing intersects the MAC around 28 months (Fig. 1e and Table 1).

For comparison, the MAC of $\mu$ commencing with several other initial conditions optimized for other time intervals $\tau$ ranging from 1 to 12 months is also shown in Fig. 1 (blue curves in the right panels). The MAC estimated from several other initial conditions remains below the corresponding maximum growth in all experiments. In addition, it also suggests that an initial state that is optimal for one $\tau$ does not need to be optimal for another (see also, for example, Fig. 4 in PS95). In the present study, the growth is "optimal" in the sense that of all possible conditions of unit amplitude, it evolves into the long-time-scale state vector at time $t=\tau$ (e.g., PS95).

The spatial patterns of optimal initial perturbations related to the largest growth (obtained from the leading eigenvector $\varphi_{1}$ when $\tau=7$ and 9 months for HadISST and ACCESS-O in the SST-only experiment) are shown in Fig. 2a and Fig. 3a. The optimal structures from the observations (Fig. 2a) and simulation (Fig. 3a) bear a strong resemblance with cooler-thannormal SST anomalies along the cold tongue region in the central to eastern equatorial Pacific and high-low-high-low structures spreading in the extratropical South Pacific from eastern Australia to South America. El Niño in the tropical Pacific and the positive SPDO in the South Pacific coevolve into their peak phases over 7 months in the observations (Fig. 2) and over 9 months in the simulation (Fig. 3), respectively.

It is of interest to point out that the optimal initial SST conditions in the extratropical South Pacific from the SST-only experiment (i.e., Figs. 2a and 3a) resemble the features of the SPMM [e.g., Fig. 1c in Liguori and Di Lorenzo (2019)]. Although the amplitudes shown in the initial conditions (Figs. 2a and 3a) are not strong, it is worth noting that any subtle perturbations identified in the initial conditions could evolve into the maximum amplitudes given the properties of the eigenvectors. Our results are consistent with previous findings, which show that the SPMM is the extratropical precursor of the tropical ENSO variability (Liguori and Di Lorenzo (2019) and references therein). In addition, the SPMM-like variability could also be the optimal precursor of the SPDO variability in advance of 7 and 9 months in the observations and simulation, respectively.

Figure 4 shows the optimal initial conditions and final peak structures for SST in the tropical Pacific and South Pacific and VAT in the South Pacific. By including subsurface processes in the South Pacific Ocean, the optimal growth time increases to 12 months (Table 1). Interestingly, we can see that the very weak loadings in the SST field in the tropical and South Pacific at the initial states (Figs. 4a,c) amplify nearly linearly, as the subsurface SPDO (Fig. 4e) develops in the South Pacific and as the ENSO variability in the tropical Pacific starts growing, evolving to the corresponding peak phase (Fig. 4b) in 12 months. That small optimal perturbation specific to the South and tropical Pacific Oceans evolves to capture a future ENSO event. It suggests that forecasts initialized using closely related optimal perturbations, that is, singular vectors (Palmer and Zanna 2013), specific to the upper ocean decadal variability in the subtropical South Pacific, have the potential to project onto future states of tropical ENSO variability.

The optimal initial VAT conditions (Fig. 4e) highlight the subtropical region east of $180^{\circ}$ longitude, where previous literature (e.g., Maharaj et al. 2005; O'Kane et al. 2014; Lou et al. 2019, 2020) suggests that baroclinic Rossby waves tend to be amplified and trapped by the bottom topography, and in particular in the vicinity of the Kermadec Ridge, acting as a potential source of decadal variability and predictability (e.g., Fig. 4 in Lou et al. 2019). The evolving VAT patterns in the South Pacific over the following 12 months (not shown) resemble the optimal initial conditions (Fig. 4e) but increase amplitudes as time evolves.

To further quantify whether the final evolved structures capture the ENSO's spatiotemporal characteristics and the SPDO well, we projected the peak phases (Figs. 4b,d,f) onto the corresponding SST and VAT anomalies to reconstruct the time series. Figure 5 shows the reconstructed time series of the peak phases and the corresponding time series of the SST ENSO, SST SPDO, and VAT SPDO. We can see that the reconstructed time series resemble the simulated ENSO and SPDO variability with temporal correlations of $0.95,0.97$, and 0.97 , respectively. The reconstructed time series (not shown) of the optimal initial VAT conditions (i.e., Fig. 4e) is highly correlated to the VAT SPDO $(r=0.95)$ but with reduced amplitude, suggesting that the subsurface South Pacific Ocean persists its signal from the initial states to the final peaks and modulates the surface ENSO and SPDO evolutions.

\section{b. Stochastic forcing}

The stochastic forcing $\mathbf{N}$ of the system [see Eq. (1)] can be estimated using a centered difference approximation (e.g., Penland and Hartten 2014; Thomas et al. 2018):

$$
\mathbf{N}(t) \approx \frac{[\mathbf{x}(t+\Delta t)-\mathbf{x}(t-\Delta t)]}{2 \Delta t}-\mathbf{L x}
$$

where $\mathbf{N}(t)$ empirically estimates the nondeterministic stochastic forcing and $\mathbf{x}$ is the finely resolved (in time) state vector. 

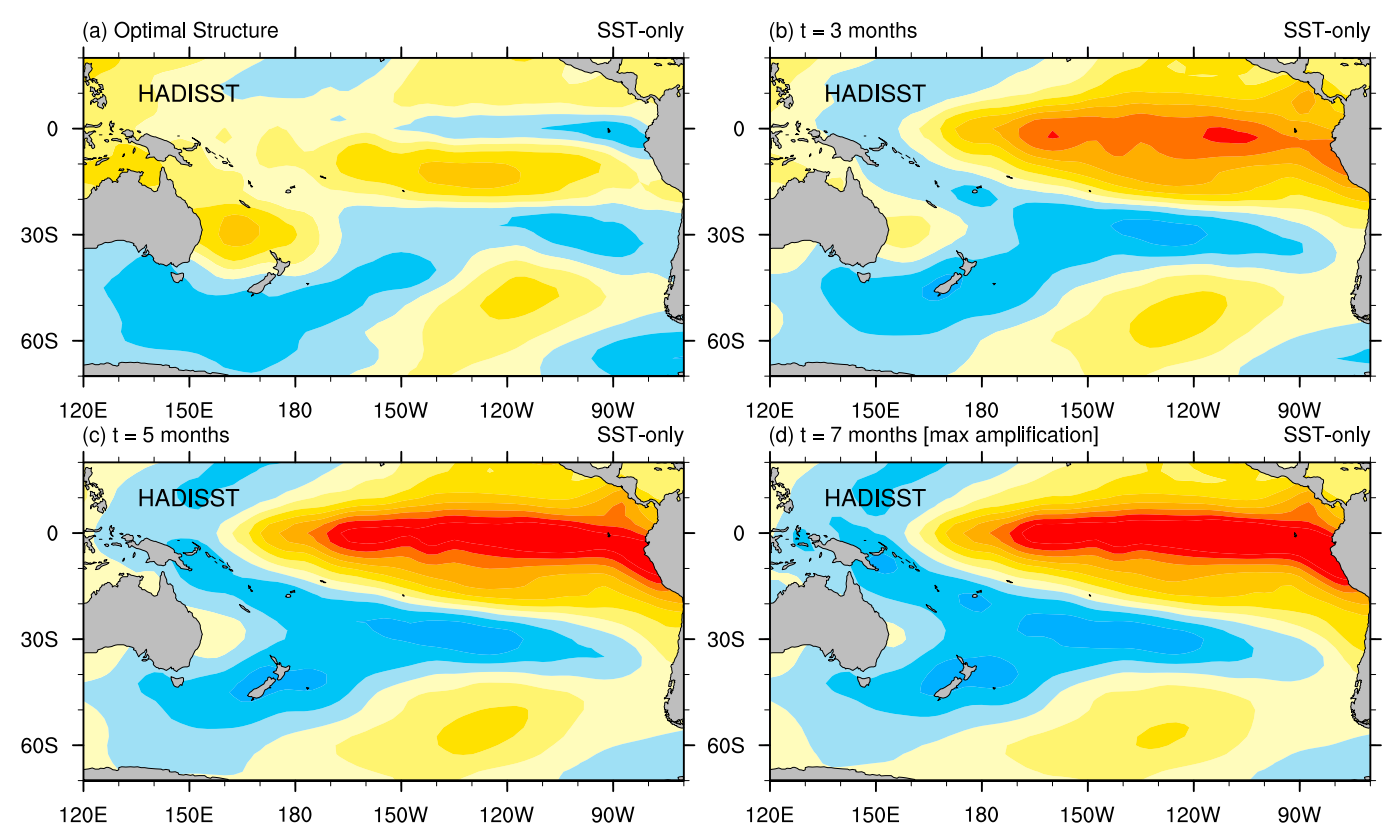

FIG. 2. Evolution of the optimal perturbations for the SST-only experiment in HadISST: (a) optimal initial conditions (optimal structure), (b),(c) optimals at $t=3$ and 5 months, and (d) optimals at the maximum amplification time, $t=7$ months. The contour interval is the same in all panels but is arbitrary.

In this study, we made use of the daily OISST product [i.e., $\Delta t=1$ day in Eq. (5)]. Constrained by the availability of daily data, we truncated the time period to 1982-2007 (26-yr period of overlap with monthly HadISST and ACCESS-O products) to make best use of the daily OISST products. The LIMs were then rebuilt based on the truncated time period. Robustness of the LIMs is demonstrated by the fact that the dynamical operators $\mathbf{L}$ and optimal growth derived from different datasets (results are not shown but statistically indistinguishable as in Fig. 1) are not sensitive to the choice of time period (i.e., 19482007 or 1982-2007) used to define the LIMs.

As described in Penland and Hartten (2014) and Thomas et al. (2018), the central difference approximation is only valid as the time interval $\Delta t$ goes to zero, which is justified if the time
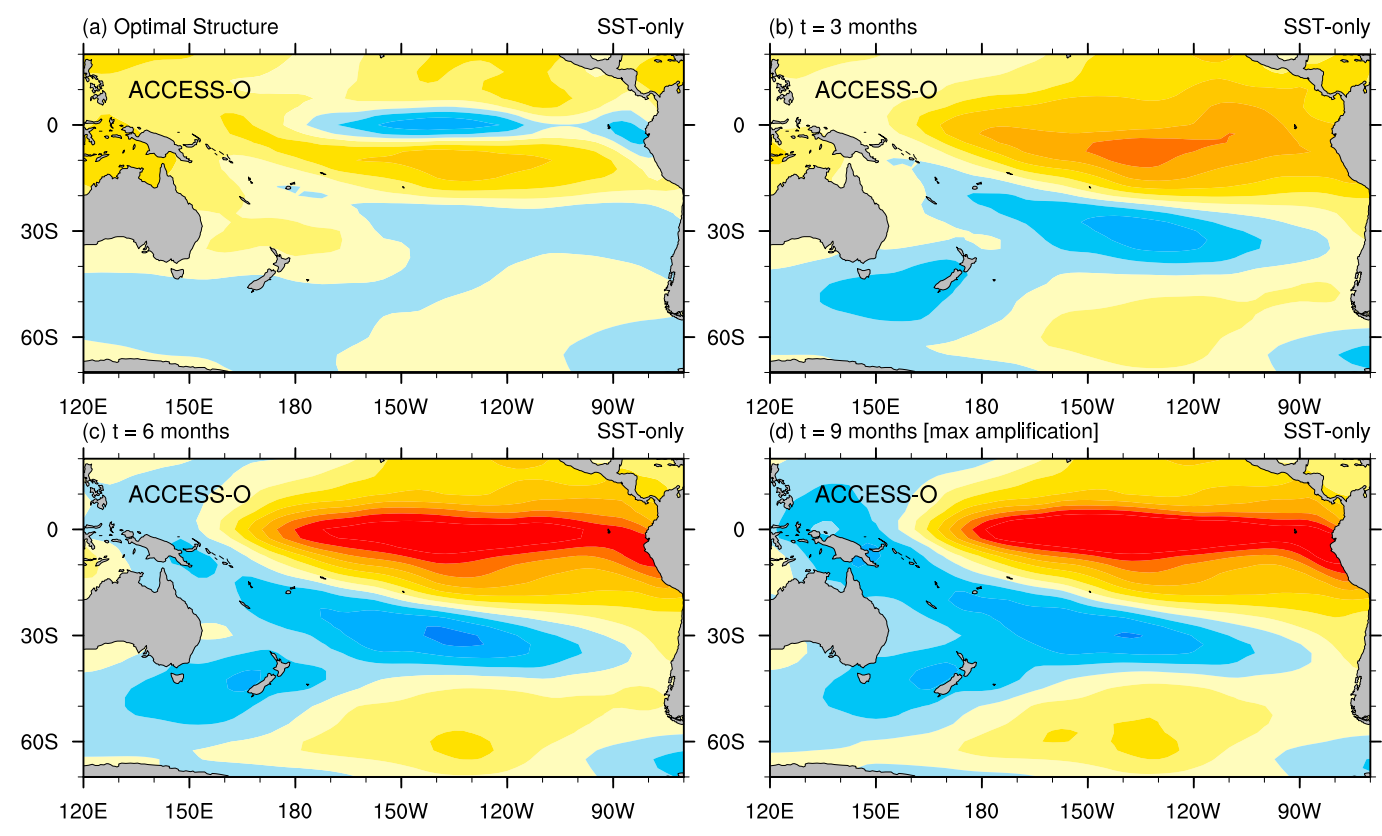

FIG. 3. As in Fig. 2, but for the ACCESS-O. 

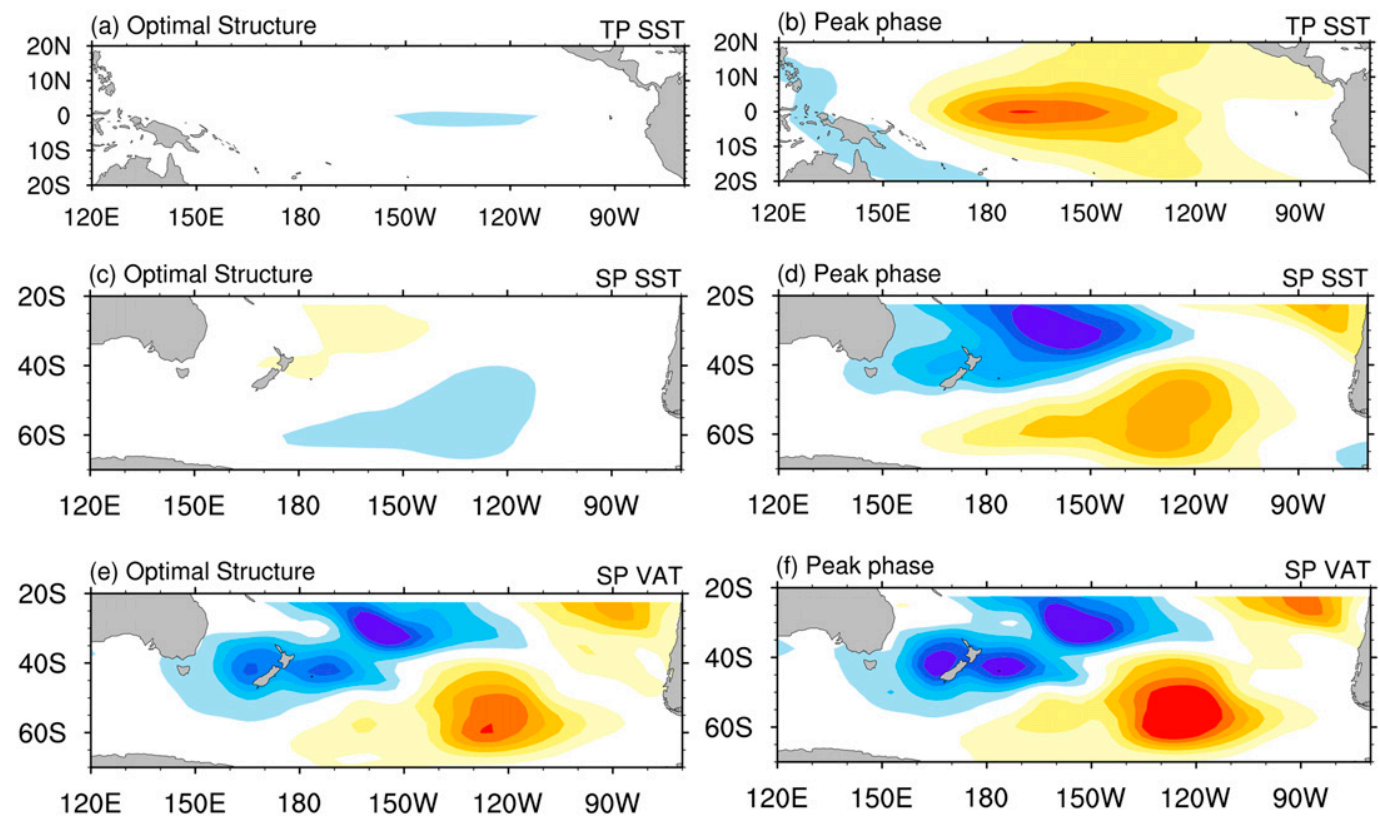

FIG. 4. The optimal initial perturbations and final structures for the SST + VAT experiment in ACCESS-O: optimal structures for (a) TP SST, (c) SP SST, and (e) SP VAT. Peak phases for (b) TP SST, (d) SP SST, and (f) SP VAT at the maximum amplification time, $t=12$ months.

scale evaluated is much shorter relative to that of the linearized deterministic system. Therefore, we make use of the daily SST anomalous data in the present study to investigate the nondeterministic stochastic forcing. The finely resolved (in time) state vector $\mathbf{x}$ in Eq. (5) is then defined as the projection of the daily SST anomalies onto the monthly leading 4 and 6 SST EOFs from the TP and SP, respectively (as described in section 2c). Note that we only investigate the stochastic forcing based on the SST-only experiments due to there being no available observed VAT datasets of sufficient spatial or temporal resolution and of a sufficiently long time period. Finally, the daily evolving stochastic forcing term $\mathbf{N}(t)$ is estimated as a residual from Eq. (5), which can be regarded as the nondeterministic contribution arising from the noise.

In our study, we first projected the monthly leading SST EOFs derived from HadISST and ACCESS-O, respectively, onto the daily SST anomalies to define the finely resolved (in time) state vectors. Then, the centered difference approximation shown in Eq. (5) was applied to estimate the nondeterministic noise term as the residual by removing the deterministic term from the actual tendency. Figure 6 shows the noise time series' spectral analysis and the corresponding deterministic time series related to ENSO and the SPDO. We can see that although the noise time series associated with ENSO and the SPDO in both the observations and simulation (Figs. 6a-d) exhibit weak red noise trends primarily due to the limited samples of the available data, the spectra are, in general, evenly distributed across different frequency bands, indicating that the noise time series estimated from Eq. (5) can be approximately regarded as nondeterministic white noise. Meanwhile, Kolmogorov-Smirnov tests have been applied to all the noise time series in the present study. The results suggest that the noise time series distributions are significantly Gaussian ( $>95 \%$ significance level). For comparison, the deterministic time series related to ENSO and the SPDO optimal initial conditions are also shown in Fig. 6 (i.e., Figs. 6e-h). We can see that the deterministic time series associated with ENSO and the SPDO (Figs. 6e-h) display strong red noise trends with increased energy across the low-frequencies and decreased energy across the high frequencies. However, due to the strong autocorrelations of the deterministic time series and the short length of the data, values of statistically significant power (at the $95 \%$ confidence level) are often too difficult to achieve (Folland et al. 1999). In summary, linear inverse modeling assumes that the noise forcing is spectrally white regarding its deterministic time scales, which has been confirmed by the spectral analysis shown in Fig. 6.

Lou et al. (2019) demonstrate that the atmospheric PSA variability is the critical and significant stochastic forcing required to generate the observed SPDO using simplified univariate AR1 models. We might expect to see that the stochastic ENSO and SPDO forcing estimated from a more generalized multivariate LIM should also be related to the observed atmospheric PSA variability. To identify the spatial patterns of the daily stochastic forcing associated with the ENSO and SPDO optimal initial conditions, we regressed the corresponding noise time series estimated from both the observations and simulation onto the daily surface pressure anomalies from the NCEP-NCAR reanalysis dataset.

The resulting regression maps are shown in Fig. 7 for the daily noise forcing in the observations and simulation, respectively, with consistent structures seen over the extratropical South Pacific. Although the regression maps do not necessarily indicate specific mechanisms that guarantee ENSO and SPDO growth in this case, they do identify some 
(a)TP SST

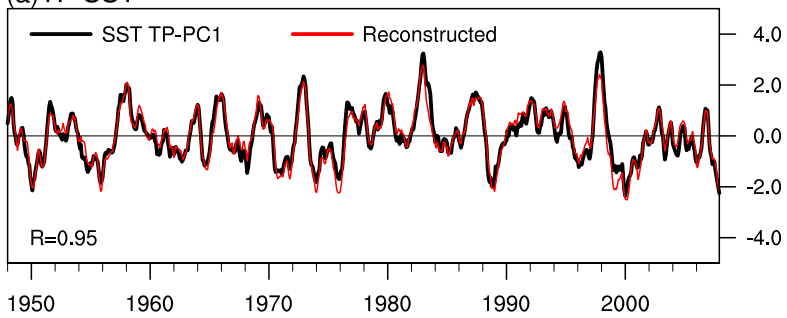

(b)SP SST

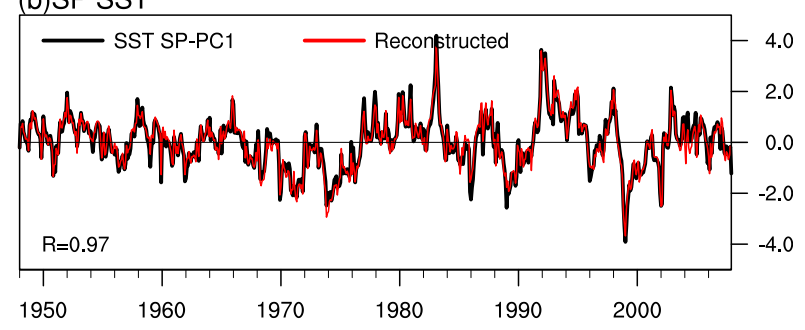

(c)SP VAT

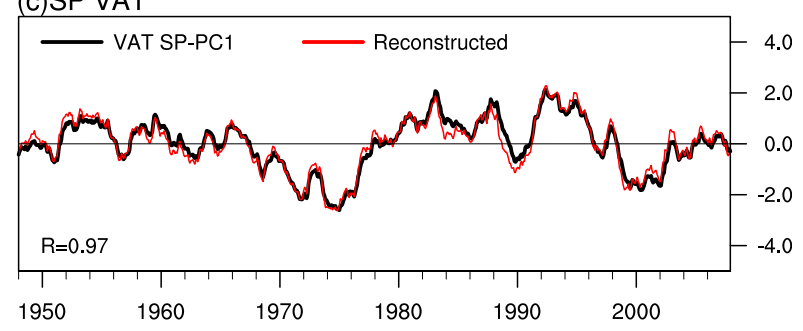

FIG. 5. Reconstructed time series (red curves) of the peak phases shown in Figs. 4b, 4d, and 4f, and the corresponding time series of the SST ENSO, SST SPDO, and VAT SPDO (black curves) defined as the leading PC of the SST and VAT anomalies in the tropical Pacific and South Pacific in ACCESS-O, respectively.

atmospheric patterns that covary with the noise forcing associated with ENSO and the SPDO optimal evolutions. Thus, the regression maps shown in Fig. 7 may be interpreted as the atmospheric variability that covaries with the noise forcing of a given set of optimal initial conditions of ENSO and the SPDO.

The atmospheric structures of the noise forcing associated with the ENSO optimal initial conditions (i.e., Figs. 7a,b) are similar to the spatial patterns of the SPO [i.e., Fig. 1a in You and Furtado (2017)] and the PSA1 [e.g., Fig. 2 in O'Kane et al. (2017)]. The results here are consistent with previous literature (e.g., Okumura 2013; You and Furtado 2017), showing that the atmospheric PSA1 and SPO play an important role in triggering the tropical ENSO variability. The noise structures related to the SPDO optimal initial conditions (Figs. 7c,d) resemble the ENSO noise forcing (shown in Figs. 7a,b) but with anomalies moving eastward. The spatial pattern is similar to the PSA2 [e.g., Fig. 1 in Mo (2000); Fig. 2 in O'Kane et al. (2017)], which was proposed as the third mode derived from some atmospheric variables (e.g., sea level pressure and 500hPa geopotential height). Previous studies (e.g., Mo 2000) argue that the PSA1 and PSA2 depict an eastward-propagating wave train mode with their phases in quadrature. Recently, some studies find that the PSA variability is linked to the tropical ENSO variability (e.g., Okumura 2013) and the extratropical SPDO variability (e.g., Lou et al. 2019). These atmospheric noise patterns indicate that the PSA variability (i.e., the PSA1 and PSA2) is strongly associated with stochastic forcing that could lead to the maximum deterministic growth of ENSO and the SPDO in the tropical and South Pacific Oceans.

Figure 7 shows that the PSA-like variability provides noise forcing associated with the ENSO and SPDO optimal initial conditions. However, our interest is to qualify to what extent the PSA variability contributes to the entire unpredictable SST component of the reduced-order system [i.e., $\mathbf{N}(t)$ in Eq. (5)]. Thus, we applied the regression vector technique documented in Penland and Hartten (2014) to estimate the PSA1 and PSA2 contribution to the unpredictable SST forcing. Here, the contribution of the PSA variability to $\mathbf{N}(t)$ is represented by $\mathbf{R} \eta(t)$, where $\eta(t)$ is the daily PSA1 or PSA2 time series, defined as the second and third EOF/PC modes of the daily surface pressure anomalies. The spatial patterns of the daily PSA1 and PSA2 (not shown) remain similar to those derived from the monthly anomalies and explain $6.7 \%$ and $6.2 \%$ of the total variance, respectively. We then stratified the data by month and regressed each month's $\mathbf{N}(t)$ onto $\eta(t)$ to estimate annually periodic regression vectors $\mathbf{R}_{\text {month, }}$ which describe the PSA contributions to the entire stochastic SST forcing.

Since $\mathbf{N}(t)$ estimated from the observations and simulation gave us indistinguishable results (e.g., Fig. 6), for the convenience of display, we only discuss the PSA contribution to the SST forcing based on HadISST in the following text.

Figure 8 shows the PSA1 contribution to the stochastic SST forcing in the tropical and South Pacific Oceans. Although the spatial patterns shown in Fig. 8 resemble the deterministic dynamics, it is worth noting that the corresponding time scales of the SST forcing are much shorter than those of the deterministic system (see Fig. 6). We can see that the PSA1 is most influential in the extended austral summer (i.e., DecemberMarch). Further, although the strongest sensitivity is shown in the South Pacific domain (Fig. 8), there is evidence suggesting that the PSA1 can modulate the stochastic SST forcing related to the tropical ENSO variability, especially in austral fall (March-May in Figs. 8c-e), and in austral spring (SeptemberNovember in Figs. 8i-k).

The PSA2 contribution to the stochastic SST forcing is shown in Fig. 9. A zonal wave train pattern extending from eastern Australia to Argentina can be observed throughout the entire year with the PSA2 being most influential in austral summer (i.e., DJF shown in Figs. 9i,a,b). Unlike the all-yearround influence in the South Pacific, we can also see that the PSA2 has strong seasonality in affecting the tropical stochastic forcing related to ENSO (e.g., January-April in Figs. 9a-d, and November in Fig. 9k).

\section{Summary and discussion}

Using a linear inverse modeling approach, we have investigated the optimal initial conditions and growth for perturbations that maximize specified final states. The role of nondeterministic stochastic forcing has been analyzed using a central difference approximation under the LIM framework. 

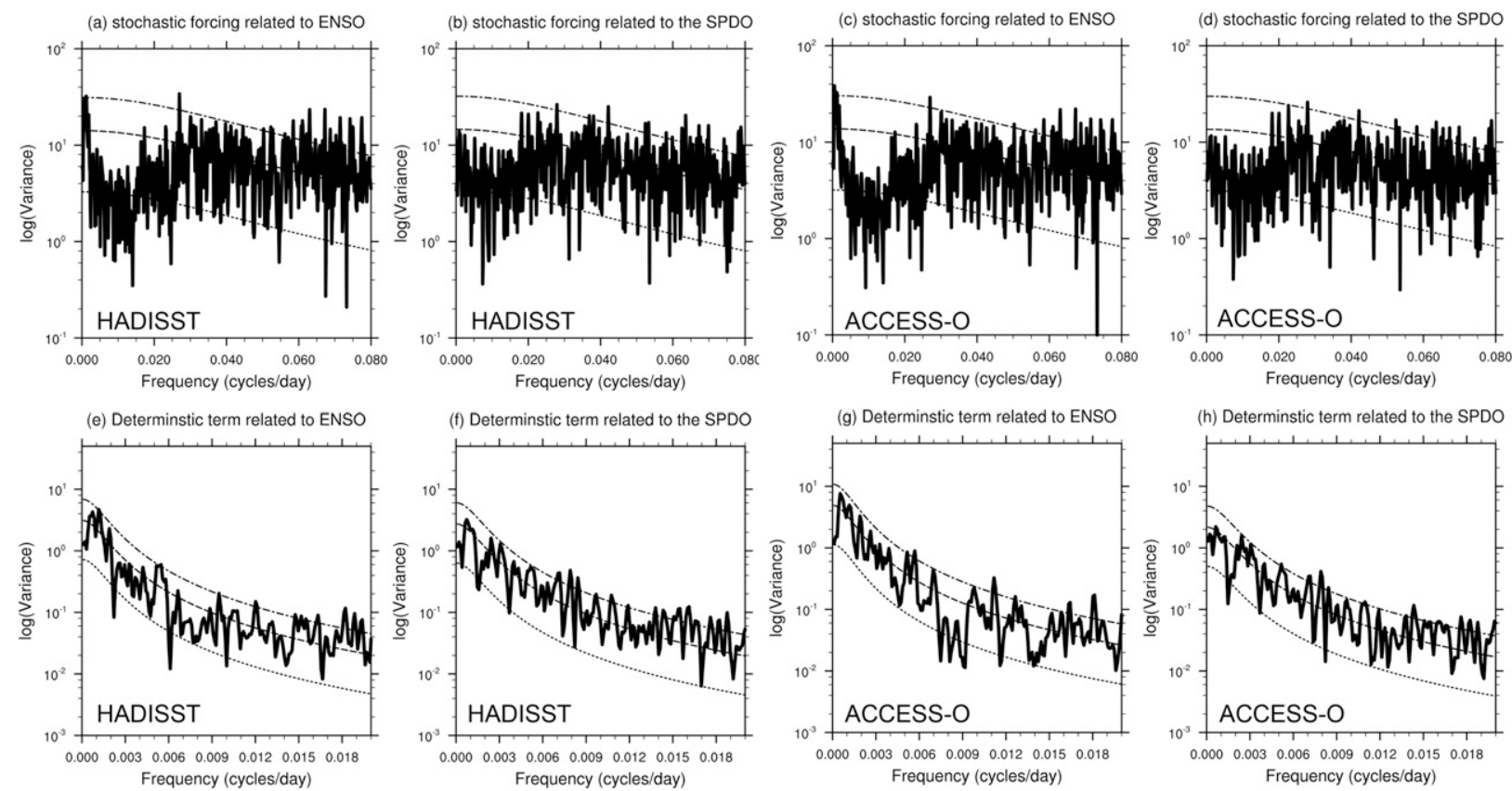

FIG. 6. The spectrum of the (a)-(d) noise time series and (e)-(h) deterministic time series related to ENSO and the SPDO in HadISST and ACCESS-O. The dashed curve in the middle of each plot indicates the red noise trend, and the upper and lower dashed curves in each plot indicate the confidence intervals ranging from $5 \%$ to $95 \%$.

When only considering SST from the tropical Pacific and South Pacific, the coupled SST system takes about 7-9 months for the optimal initial perturbations to grow into the specified peak phases, in agreement with previous ENSO studies (e.g.,
PS95; Vimont et al. 2014 and references therein). In most previous tropical ENSO studies, low-pass-filtering techniques are applied to remove subseasonal fluctuations, whereas we used the combined monthly unfiltered SST anomalies from
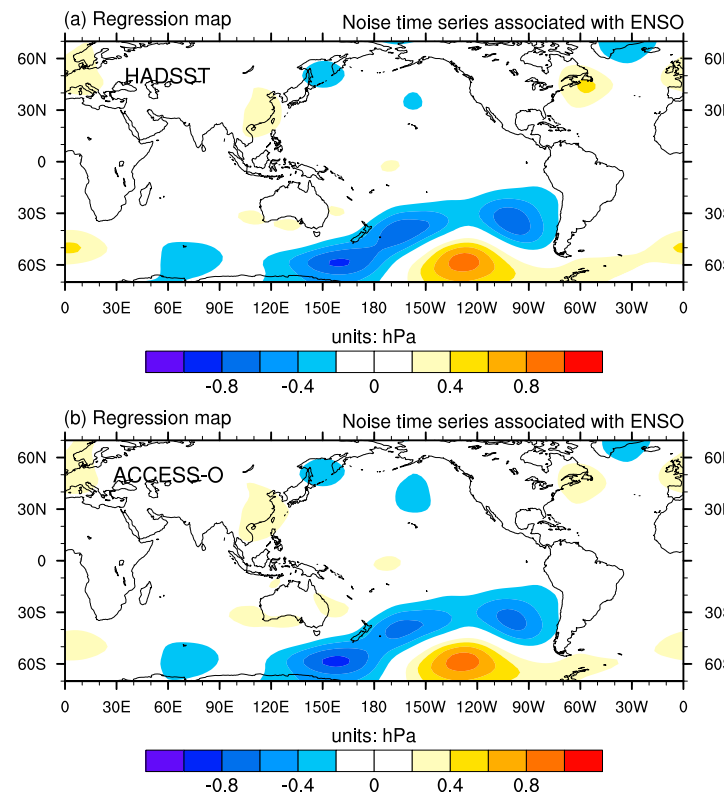

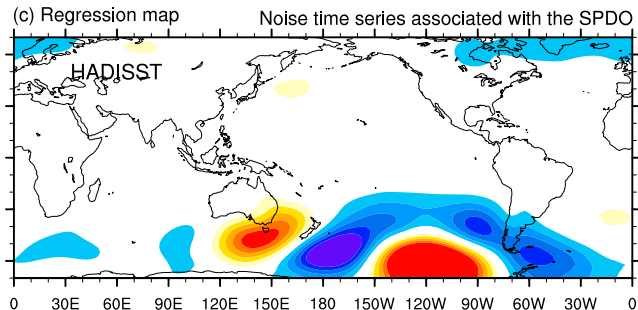

units: $\mathrm{hPa}$

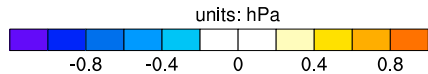

(d) Regression map Noise time series associated with the SPDO

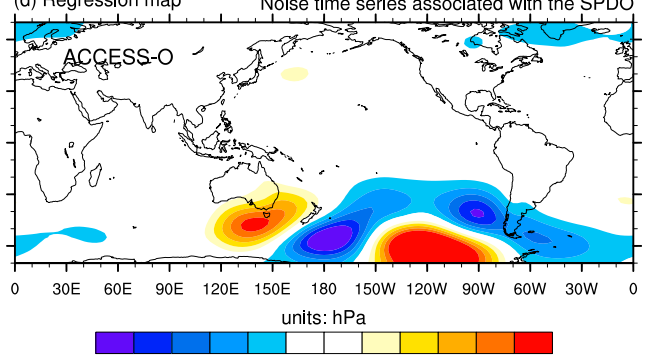

FIG. 7. Atmospheric noise structures associated with (left) ENSO and (right) the SPDO optimal initial conditions in HadISST and ACCESS-O. Shown are the daily regression maps between the daily surface pressure anomalies from NCEP-NCAR reanalysis and the daily noise forcing time series related to ENSO and the SPDO optimal initial conditions. 


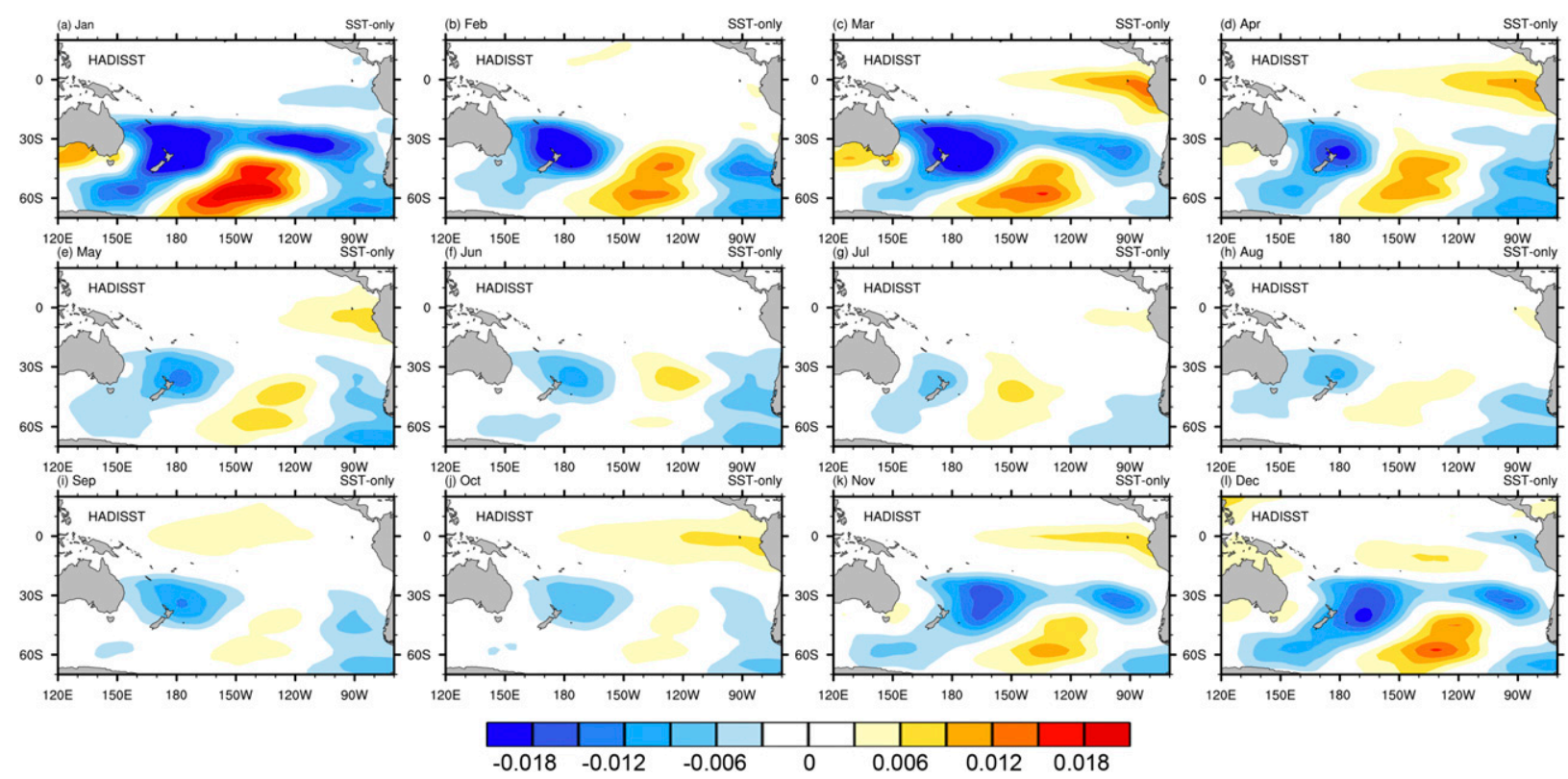

FIG. 8. The PSA1 contribution to the stochastic SST forcing. Shown are the monthly variations of the regression vector R. See text for details.

both the tropical Pacific and South Pacific in the present study. The consistent results from filtered and unfiltered data suggest that the South Pacific acts as a natural dynamical low-pass filter to the tropical dynamics, and thus sets the background state to modulate the decadal ENSO variability remotely.

The optimal growth period that maximizes the SPDO peak amplifications increases to 12 months when subsurface processes (i.e., characterized simply as VAT) are incorporated. The signals arising from the region to the east of $180^{\circ}$ in the subtropical South Pacific (Fig. 4) are highlighted in the evolution of the SPDO, consistent with previous studies (e.g., O'Kane et al. 2014; Lou et al. 2019), showing that trapped baroclinic Rossby waves interacting with bottom topography act as an important source of decadal variability and predictability of the SPDO in this region. That optimal initial perturbations with weak tropical expression evolve to include ENSO-like structures (Fig. 4) further suggests that the subsurface plays an important role for the subtropical South Pacific in determining tropical ENSO variability and predictability.

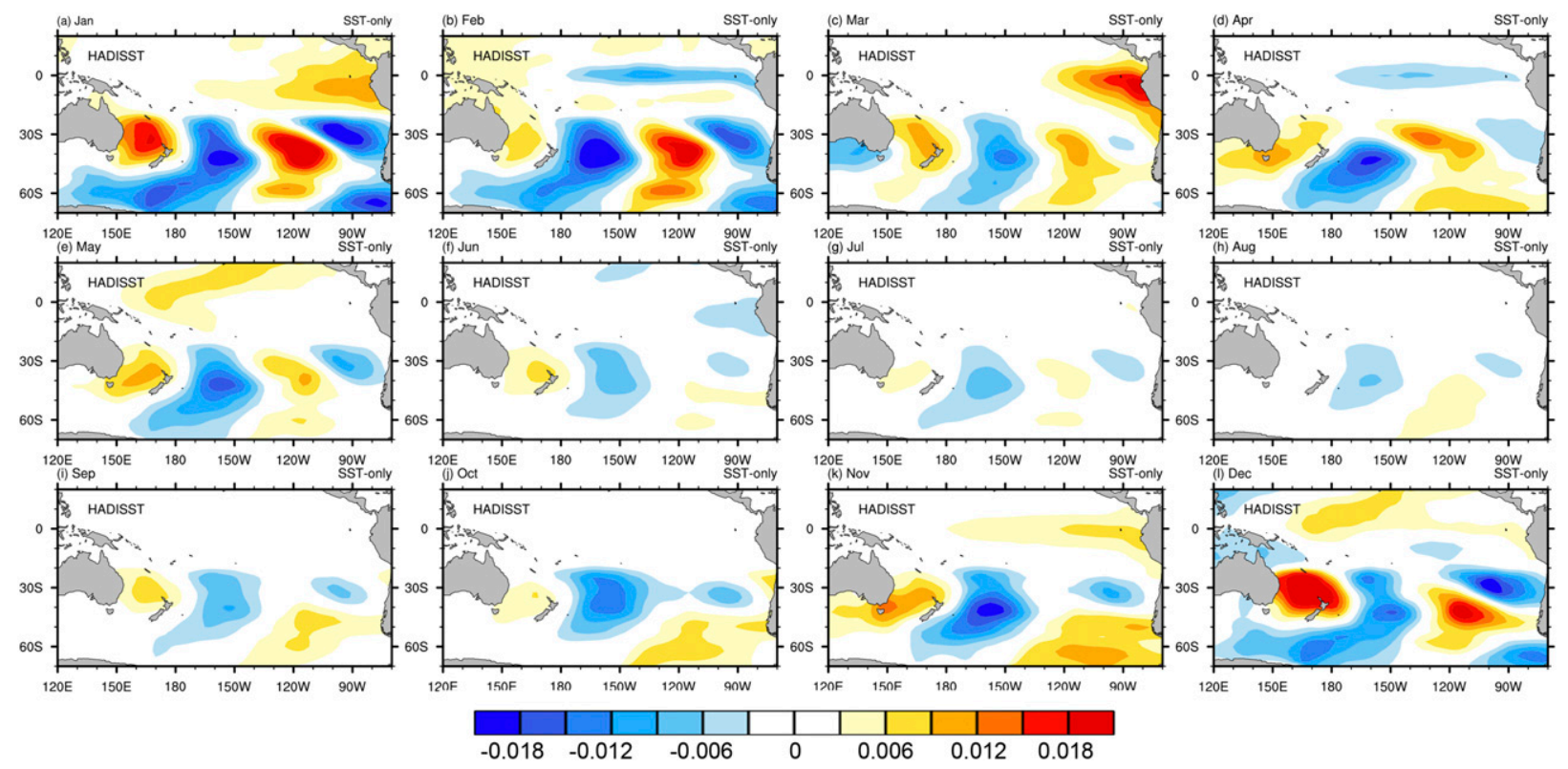

FIG. 9. Similar to Fig. 8, but for the PSA2 contribution to the stochastic SST forcing. 
The predictability of the linearized system depends not only on its own dynamics but also on the contribution due to the stochastic forcing (i.e., in the absence of stochastic forcing, the linearized deterministic system eventually decays). Nevertheless, growth can still be sustained for around 19 months by modal interference when only considering SST, which defines an optimistic limit to the potential predictability of the system. When subsurface South Pacific processes are incorporated, the potential predictability increases to about 44 months (Table 1 ).

On the one hand, stochastic forcing is crucial for sustaining the system dynamically. On the other hand, predictability is lost as a result of stochastic forcing that is unpredictable over the longer time scales of the deterministic dynamics. For a deterministic system to be predictable, we might expect that the energy growth of the linearized system has to be larger than the error variance growth, which defines a more practical limit to the predictability of the linearized system. Using this criterion, the limit of practical predictability was found to be around 16 months if only considering SST, increasing to around 30 months (Table 1) when subsurface South Pacific processes are incorporated. Although unpredictable over longer time scales, stochastic forcing is nevertheless crucial in setting up the optimal initial states and in determining the characteristic damping time scales and oscillatory periods of the SPDO.

In the present study, we have characterized the spatiotemporal features of stochastic forcing. Although we cannot estimate the stochastic forcing term directly in this inverse method, it is possible to use the residual by removing the deterministic dynamics from the actual tendency, to infer the nondeterministic stochastic forcing. By applying the central difference approach under a generalized LIM framework, we have shown that the resulting stochastic forcing time series satisfy the Gaussian white noise assumptions of linear inverse modeling. We found that the PSA variability (i.e., the PSA1 and the PSA2) contributes not only to the ENSO and SPDO optimal initial conditions, but in general to the entire stochastic SST forcing in our reduced-order system, especially in austral summer (DJF).

The linear inverse modeling technique applied in this study has some other limitations. First, due to nonlinearity, nonstationarity, or instability of the actual processes being sampled, we have to truncate the entire system by applying EOF analysis to reduce the spatial degrees of freedom of our tropical, and South Pacific combined system. The reliance on a truncated EOF space limits the dimensionality of the deterministic dynamics. In addition, the LIM method assumes its stochastic forcing has much shorter memory (i.e., rapidly decorrelated) than the linearized deterministic dynamics. If this assumption cannot be satisfied, the constructed LIM is therefore invalid.

A variety of validation tests should always be conducted before a LIM becomes useful. By applying tau tests and a fluctuation-dissipation relation test, Lou et al. (2020) show that the LIM performs well in the South Pacific. More tests have been conducted into the stochastic forcing in the present study, suggesting that the resulting stochastic forcing satisfies the Gaussian white noise assumption. However, due to the relatively short length of the record used to construct the LIM, some deterministic and noise effects can be convolved [as documented in, e.g., Thomas et al. (2018)]. Meanwhile, since the LIM has an inherent linear damping time scale, ensemble LIM forecasts are not possible as an alternative to global forecast systems (Lou et al. 2020). Nevertheless, the LIM provides a useful benchmark to understand the linearized dynamics and predictability.

The present study identified some optimal initial structures and stochastic forcing related to the atmospheric PSA variability. However, it is worth noting that the development of ENSO and the SPDO can be affected by a wide variety of initial states and stochastic structures. In addition, we stressed the important role of the PSA variability in contributing to stochastic SST forcing, while stochastic forcing itself represents a blend of a variety of modes of variability that can excite growth in the deterministic dynamics. Hence, the relative importance of the PSA variability in generating the stochastic forcing might vary from case to case and remains an important topic to be further investigated.

Acknowledgments. JL is grateful for a Ph.D. scholarship provided by the ARC Centre of Excellence for Climate System Science (CE110001028), a University of Tasmania tuition fee scholarship, and a CSIRO-UTAS Quantitative Marine Science top-up scholarship [including support from the Australian Commonwealth Scientific Research Organisation (CSIRO) Postgraduate scheme]. TJO was supported by the CSIRO Decadal Climate Forecasting Project (https://research.csiro.au/dfp). NJH gratefully acknowledges funding support from the ARC Centre of Excellence for Climate Extremes (CE170100023) and Australian Government National Environmental Science Programme Earth Systems and Climate Change Hub (NESP ESCC).

\section{REFERENCES}

Alexander, M. A., L. Matrosova, C. Penland, J. D. Scott, and P. Chang, 2008: Forecasting Pacific SSTs: Linear inverse model predictions of the PDO. J. Climate, 21, 385-402, https:// doi.org/10.1175/2007JCLI1849.1.

Amaya, D. J., 2019: The Pacific meridional mode and ENSO: A review. Curr. Climate Change Rep., 5, 296-307, https://doi.org/ 10.1007/s40641-019-00142-x.

Capotondi, A., and P. D. Sardeshmukh, 2015: Optimal precursors of different types of ENSO events. Geophys. Res. Lett., 42, 9952-9960, https://doi.org/10.1002/2015GL066171.

— Lett., 44, 8548-8556, https://doi.org/10.1002/2017GL074515.

,$- \ldots$, and L. Ricciardulli, 2018: The nature of the stochastic wind forcing of ENSO. J. Climate, 31, 8081-8099, https:// doi.org/10.1175/JCLI-D-17-0842.1.

Cavanaugh, N. R., T. Allen, A. Subramanian, B. Mapes, H. Seo, and A. J. Miller, 2014: The skill of atmospheric linear inverse models in hindcasting the Madden-Julian oscillation. Climate Dyn., 44, 897-906, https://doi.org/10.1007/s00382-014-2181-x.

Chen, X., and J. M. Wallace, 2015: ENSO-like variability: 19002013. J. Climate, 28, 9623-9641, https://doi.org/10.1175/JCLID-15-0322.1.

Chung, C. T. Y., S. B. Power, A. Sullivan, and F. Delage, 2019: The role of the South Pacific in modulating tropical Pacific variability. Sci. Rep., 9, 18311, https://doi.org/10.1038/s41598-019-52805-2.

Delworth, T. L., and Coauthors, 2006: GFDL's CM2 global coupled climate models. Part I: Formulation and simulation 
characteristics. J. Climate, 19, 643-674, https://doi.org/10.1175/ JCLI3629.1.

Di Lorenzo, E., and M. D. Ohman, 2013: A double-integration hypothesis to explain ocean ecosystem response to climate forcing. Proc. Natl. Acad. Sci. USA, 110, 2496-2499, https:// doi.org/10.1073/pnas.1218022110.

Ding, R., J. Li, and Y. Tseng, 2014: The impact of South Pacific extratropical forcing on ENSO and comparisons with the North Pacific. Climate Dyn., 44, 2017-2034, https://doi.org/ 10.1007/s00382-014-2303-5.

Folland, C. K., D. E. Parker, A. W. Colman, and R. Washington, 1999: Large scale modes of ocean surface temperature since the late nineteenth century. Beyond El Niño, A. Navarra, Ed., Springer, 73-102.

Frankignoul, C., and K. Hasselmann, 1977: Stochastic climate models, Part II. Application to sea-surface temperature anomalies and thermocline variability. Tellus, 29, 289-305, https://doi.org/10.3402/tellusa.v29i4.11362.

Gehne, M., R. Kleeman, and K. E. Trenberth, 2014: Irregularity and decadal variation in ENSO: A simplified model based on principal oscillation patterns. Climate Dyn., 43, 3327-3350, https://doi.org/10.1007/s00382-014-2108-6.

Griffies, S. M., and Coauthors, 2009: Coordinated Ocean-Ice Reference Experiments (COREs). Ocean Modell., 26 (1-2), 1-46, https://doi.org/10.1016/j.ocemod.2008.08.007.

Hasselmann, K., 1976: Stochastic climate models Part I. Theory. Tellus, 28, 473-485, https://doi.org/10.3402/tellusa.v28i6.11316.

Huddart, B., A. Subramanian, L. Zanna, and T. Palmer, 2016: Seasonal and decadal forecasts of Atlantic sea surface temperatures using a linear inverse model. Climate Dyn., 49, 18331845, https://doi.org/10.1007/s00382-016-3375-1.

Larson, S. M., K. V. Pegion, and B. P. Kirtman, 2018: The South Pacific meridional mode as a thermally driven source of ENSO amplitude modulation and uncertainty. J. Climate, 31, 51275145, https://doi.org/10.1175/JCLI-D-17-0722.1.

Liguori, G., and E. Di Lorenzo, 2019: Separating the North and South Pacific meridional modes contributions to ENSO and tropical decadal variability. Geophys. Res. Lett., 46, 906-915, https://doi.org/10.1029/2018GL080320.

Liu, Z., and E. Di Lorenzo, 2018: Mechanisms and predictability of Pacific decadal variability. Curr. Climate Change Rep., 4, 128144, https://doi.org/10.1007/s40641-018-0090-5.

Lou, J., N. J. Holbrook, and T. J. O'Kane, 2019: South Pacific decadal climate variability and potential predictability. J. Climate, 32, 6051-6069, https://doi.org/10.1175/JCLI-D-18-0249.1.

_, T. J. O'Kane, and N. J. Holbrook, 2020: A linear inverse model of tropical and South Pacific seasonal predictability. J. Climate, 33, 4537-4554, https://doi.org/10.1175/JCLI-D-19-0548.1.

Lu, F., Z. Liu, Y. Liu, S. Zhang, and R. Jacob, 2016: Understanding the control of extratropical atmospheric variability on ENSO using a coupled data assimilation approach. Climate Dyn., $\mathbf{4 8}$, 3139-3160, https://doi.org/10.1007/s00382-016-3256-7.

Maharaj, A. M., P. Cipollini, and N. J. Holbrook, 2005: Observed variability of the South Pacific westward sea level anomaly signal in the presence of bottom topography. Geophys. Res. Lett., 32, L04611, https://doi.org/10.1029/2004GL020966.

Mantua, N. J., S. R. Hare, Y. Zhang, J. M. Wallace, and R. C. Francis, 1997: A Pacific interdecadal climate oscillation with impacts on salmon production. Bull. Amer. Meteor. Soc., 78, 1069-1080, https://doi.org/10.1175/1520-0477(1997)078<1069: APICOW $>2.0 . C O ; 2$.

Mo, K. C., 2000: Relationships between low-frequency variability in the Southern Hemisphere and sea surface temperature anomalies. J. Climate, 13, 3599-3610, https://doi.org/10.1175/ 1520-0442(2000)013<3599:RBLFVI > 2.0.CO;2.

Newman, M., 2007: Interannual to decadal predictability of tropical and North Pacific sea surface temperatures. J. Climate, 20, 2333-2356, https://doi.org/10.1175/JCLI4165.1.

— , G. P. Compo, and M. A. Alexander, 2003: ENSO-forced variability of the Pacific decadal oscillation. J. Climate, 16, 3853-3857, https://doi.org/10.1175/1520-0442(2003)016<3853: EVOTPD $>2.0 . \mathrm{CO} ; 2$.

— M. A. Alexander, and J. D. Scott, 2011: An empirical model of tropical ocean dynamics. Climate Dyn., 37, 1823-1841, https://doi.org/10.1007/s00382-011-1034-0.

O'Kane, T. J., R. J. Matear, M. A. Chamberlain, E. C. J. Oliver, and N. J. Holbrook, 2014: Storm tracks in the Southern Hemisphere subtropical oceans. J. Geophys. Res. Oceans, 119, 6078-6100, https://doi.org/10.1002/2014JC009990.

_ D. P. Monselesan, and J. S. Risbey, 2017: A multiscale reexamination of the Pacific-South American pattern. Mon. Wea. Rev., 145, 379-402, https://doi.org/10.1175/MWR-D-16-0291.1.

Okumura, Y. M., 2013: Origins of tropical Pacific decadal variability: Role of stochastic atmospheric forcing from the South Pacific. J. Climate, 26, 9791-9796, https://doi.org/10.1175/JCLI-D-13-00448.1.

Palmer, T. N., and L. Zanna, 2013: Singular vectors, predictability and ensemble forecasting for weather and climate. J. Phys., 46A, 254018, https://doi.org/10.1088/1751-8113/46/25/254018.

Penland, C., and T. Magorian, 1993: Prediction of Niño 3 sea surface temperatures using linear inverse modeling. J. Climate, $\mathbf{6}$, 1067-1076, https://doi.org/10.1175/1520-0442(1993)006<1067: PONSST $>2.0 . \mathrm{CO} ; 2$.

_ and P. D. Sardeshmukh, 1995: The optimal growth of tropical sea surface temperature anomalies. J. Climate, 8, 1999-2024, https:// doi.org/10.1175/1520-0442(1995)008<1999:TOGOTS >2.0.CO;2.

_ variability in tropical sea surface temperatures using a nonnormal filter. J. Climate, 19, 5796-5815, https://doi.org/10.1175/JCLI3951.1. , and L. M. Hartten, 2014: Stochastic forcing of north tropical Atlantic sea surface temperatures by the North Atlantic oscillation. Geophys. Res. Lett., 41, 2126-2132, https://doi.org/ 10.1002/2014GL059252.

Power, S., and R. Colman, 2006: Multi-year predictability in a coupled general circulation model. Climate Dyn., 26, 247-272, https://doi.org/10.1007/s00382-005-0055-y.

Rayner, N. A., D. E. Parker, E. B. Horton, C. K. Folland, L. V. Alexander, D. P. Rowell, E. C. Kent, and A. Kaplan, 2003: Global analyses of sea surface temperature, sea ice, and night marine air temperature since the late nineteenth century. J. Geophys. Res., 108, 4407, https://doi.org/10.1029/2002JD002670.

Reynolds, R. W., N. A. Rayner, T. M. Smith, D. C. Stokes, and W. Wang, 2002: An improved in situ and satellite SST analysis for climate. J. Climate, 15, 1609-1625, https://doi.org/10.1175/ 1520-0442(2002)015<1609:AIISAS > 2.0.CO;2.

Schnur, R., G. Schmitz, N. Grieger, and H. V. Storch, 1993: Normal modes of the atmosphere as estimated by principal oscillation patterns and derived from quasigeostrophic theory. J. Atmos. Sci., 50, 2386-2400, https://doi.org/10.1175/1520-0469(1993) $050<2386$ :NMOTAA $>2.0 . \mathrm{CO} ; 2$.

Shakun, J. D., and J. Shaman, 2009: Tropical origins of North and South Pacific decadal variability. Geophys. Res. Lett., 36, L19711, https://doi.org/10.1029/2009GL040313.

Thomas, E. E., D. J. Vimont, M. Newman, C. Penland, and C. Martínez-Villalobos, 2018: The role of stochastic forcing in generating ENSO diversity. J. Climate, 31, 9125-9150, https:// doi.org/10.1175/JCLI-D-17-0582.1. 
Vimont, D. J., M. A. Alexander, and M. Newman, 2014: Optimal growth of central and east Pacific ENSO events. Geophys. Res. Lett., 41, 4027-4034, https://doi.org/10.1002/2014GL059997.

von Storch, H., and J. Xu, 1990: Principal oscillation pattern analysis of the 30- to 60-day oscillation in the tropical troposphere. Climate Dyn., 4, 175-190, https://doi.org/10.1007/ BF00209520.

$\mathrm{Xu}$, J.-S., 1992: On the relationship between the stratospheric quasibiennial oscillation and the tropospheric Southern Oscillation. J. Atmos. Sci., 49, 725-734, https://doi.org/10.1175/1520-0469(1992) $049<0725$ :OTRBTS $>2.0 . \mathrm{CO} ; 2$.
You, Y., and J. C. Furtado, 2017: The role of South Pacific atmospheric variability in the development of different types of ENSO. Geophys. Res. Lett., 44, 7438-7446, https://doi.org/ 10.1002/2017GL073475.

Zanna, L., 2012: Forecast skill and predictability of observed Atlantic sea surface temperatures. J. Climate, 25, 5047-5056, https://doi.org/10.1175/JCLI-D-11-00539.1.

Zhang, H., A. Clement, and P. Di Nezio, 2014: The South Pacific meridional mode: A mechanism for ENSO-like variability. J. Climate, 27, 769-783, https://doi.org/10.1175/JCLI-D-1300082.1. 